\title{
40. CHEMICAL CHARACTERIZATION OF AROMATIC HYDROCARBONS, KEROGEN, AND HUMIC ACIDS IN DEEP SEA DRILLING PROJECT LEG 71 CORES ${ }^{1}$
}

\author{
E. C. Copelin and S. R. Larter, Union Science and Technology Division, \\ Union Oil Company of California, Brea, California
}

\begin{abstract}
Forty-three core samples from Sites 511 through 514 of DSDP Leg 71 were analyzed geochemically. The black shales at the bottom of Hole 511, in the basin province of the Falkland Plateau, contain an average of $1590 \mathrm{ppm}$ extractable organic matter (EOM) and 120 ppm hydrocarbons. Whereas molecular type-carbon number distributions of mono- and polynuclear aromatic hydrocarbons and their sulphur and oxygen analogues in the black shale "aromatic hydrocarbon" fractions are very similar to those of many crude oils, other data-gas chromatography (GC) fingerprint, pyrolysis GC, visual kerogen analysis, H/C ratio-suggest the black shale section is thermally immature. Together, these observations imply that many of the hydrocarbons were deposited with the original sediments or are diagenetic products of other biological compounds. Pyrograms of the humic acid and kerogen fractions from the black shale interval are typical of geopolymers derived from marine algal material. It appears that these humic acids and kerogens are derived from the same lipid stock.
\end{abstract}

\section{INTRODUCTION}

Forty-three core samples from Sites 511 through 514 of DSDP Leg 71 were analyzed for extractable organic matter (EOM), aromatic hydrocarbons, humic acids, and kerogen. The amounts of EOM and total hydrocarbons and the molecular composition of the aromatic hydrocarbons were used to evaluate the potential of the sediments as source beds for crude oil. Pyrolysis gas chromatograms of the humic acid and kerogen fractions were recorded to define the source of the insoluble organic matter in the sediments.

\section{SAMPLE SEPARATIONS AND ANALYTICAL METHODS}

Diagrams of the separation procedures appear in Figures 1 and 2. All solutions and solvents, both organic and inorganic, were of the highest purity available. Centrifugation was used to separate sediments from water or organic solvent phases. Organic solvents were stripped from extracts or eluates by heating on a steam bath under a gentle stream of nitrogen.

Each section of core was dispersed in and washed twice with water. Then the sediment was suspended in acetone and gently pulverized further in a Waring blender. Next it was extracted again with acetone and then twice more with a mixture of $70 \%$ toluene, $15 \%$ methanol, and $15 \%$ acetone (TMA). The organic extracts were combined and concentrated to yield the EOM fractions. Table 1 lists the EOM results as well as quantitative data about EOM subfractions.

The EOM fractions were dissolved in a minimum amount of methylene chloride and deasphaltened in $n$-pentane. Then the "oils" from the $n$-pentane solution were elution-chromatographed over silica gel ( $4 \%$ water). Hydrocarbons were eluted first with $2.5 \%$ toluene in $n$-pentane and nonhydrocarbons eluted with $50 \%$ methanol-toluene. Each hydrocarbon fraction was charged to a column of calcined alumina. Saturated hydrocarbons (plus any olefins) were eluted first with $7 \%$ toluene in $n$-pentane and aromatic hydrocarbons eluted with $50 \%$ methanol-toluene.

Each extracted sediment was treated with $50 \% \mathrm{HCl}$ to dissolve carbonates, then washed with water to remove soluble salts. Next the

\footnotetext{
${ }^{1}$ Ludwig, W. J., Krasheninnikov, V. A., et al., Init. Repts. DSDP, 71: Washington (U.S. Govt. Printing Office).
}

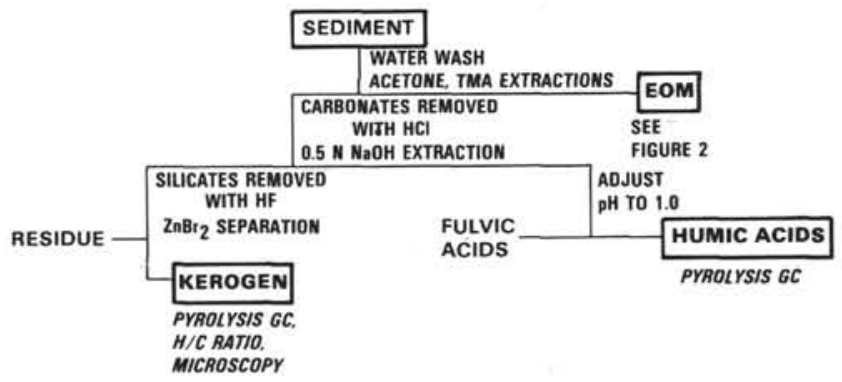

Figure 1. Procedures for separating kerogen and humic acid fractions from DSDP Leg 71 samples.

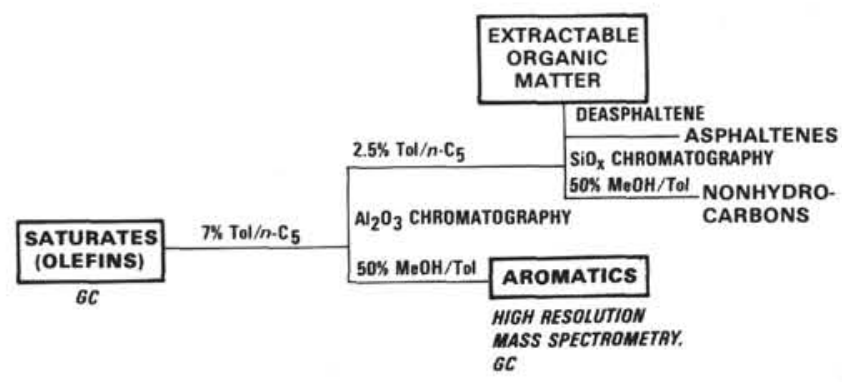

Figure 2. Procedures for separating of aromatic and saturated hydrocarbon fractions from EOM.

sediment was suspended in $0.5 \mathrm{~N} \mathrm{NaOH}$ for a day. The residue was separated from the aqueous phase first by centrifugation and then by filtration through a $0.45-\mu \mathrm{m}$ Millipore filter. After the $\mathrm{pH}$ was adjusted to 1.0 , the solution was centrifuged to isolate the precipitated humic acids (Ishiwatari et al., 1977).

Kerogens were isolated from some of the residues remaining from the Site 511 humic acid separations. After overnight treatment with hydrofluoric acid, the residues were washed with dilute $\mathrm{HCl}$ and water. The kerogens were separated from any remaining inorganic material by flotation on $1.85 \mathrm{Sp}$. G. $\mathrm{ZnBr}_{2}$ solution, after which they were solvent extracted and dried.

Pyrolysis gas chromatograms (pyrograms) were produced by pyrolyzing up to $100 \mu \mathrm{g}$ of very finely ground humic acid or kerogen at 
Table 1. Organic geochemical data for Sites 511 through 514, DSDP Leg 71.

\begin{tabular}{|c|c|c|c|c|c|c|c|c|c|}
\hline \multirow{2}{*}{$\begin{array}{l}\text { Core/ } \\
\text { Section }\end{array}$} & \multirow{2}{*}{$\begin{array}{l}\text { Sub-bottom } \\
\text { Depth } \\
\text { (m) }\end{array}$} & \multicolumn{3}{|c|}{ (ppm) } & \multicolumn{5}{|c|}{$\begin{array}{l}\text { Extractable Organic Matter } \\
(\text { wt. \%) }\end{array}$} \\
\hline & & EOM & $\mathrm{HC}$ & $\mathrm{HA}^{\mathrm{b}}$ & $\mathrm{HC}$ & SAT & AROM & HET & ASP \\
\hline \multicolumn{10}{|l|}{ Hole 511} \\
\hline $3-4$ & 20.5 & 177 & 24 & 643 & 14 & 9 & 5 & 46 & 40 \\
\hline $6-3$ & 47.5 & 130 & 14 & 1180 & 11 & 9 & 2 & 49 & 40 \\
\hline $9-5$ & 79.0 & 153 & 15 & $-c$ & 10 & 6 & 4 & 57 & 33 \\
\hline $16-1$ & 139.5 & 245 & 35 & 1750 & 14 & 10 & 4 & 37 & 49 \\
\hline $18-1$ & 158.5 & 142 & 25 & 1580 & 18 & 14 & 4 & 48 & 34 \\
\hline $24-4$ & 210.5 & 38 & 22 & 234 & 58 & 10 & 48 & 34 & 8 \\
\hline $28-5$ & 231.0 & 43 & 27 & - & 62 & so & 12 & 31 & 7 \\
\hline $31-5$ & 259.5 & 241 & 101 & 682 & 42 & 41 & 1 & 45 & 13 \\
\hline $34-5$ & 288.0 & 61 & 19 & 307 & 31 & 12 & 19 & 42 & 27 \\
\hline $37-1$ & 310.5 & 151 & 75 & 214 & 50 & 43 & 7 & 35 & 15 \\
\hline $40-4$ & 343.5 & 124 & 14 & 126 & 11 & 3 & 8 & 17 & 72 \\
\hline $43-4$ & 372.0 & 79 & 22 & 122 & 29 & 25 & 4 & 32 & 39 \\
\hline $46-2$ & 397.5 & 31 & 21 & - & 68 & 36 & 32 & 9 & 23 \\
\hline $49-4$ & 429.0 & 19 & 13 & 0 & 70 & 20 & 50 & 15 & 15 \\
\hline $52-5$ & 459.0 & 14 & 7 & - & 47 & 33 & 14 & 33 & 20 \\
\hline $55-4$ & 486.0 & 15 & 9 & 155 & 62 & 38 & 24 & 23 & 15 \\
\hline $58-3$ & 513.0 & 48 & 14 & - & 30 & 26 & 4 & 33 & 37 \\
\hline $60-5$ & 535.0 & 2017 & 206 & 127 & 10 & 5 & 5 & 31 & 59 \\
\hline $62-5$ & 554.0 & 2468 & 123 & 892 & 5 & 3 & 2 & 46 & 49 \\
\hline $64-4$ & 571.5 & 1411 & 92 & 282 & 7 & 4 & 3 & 40 & 53 \\
\hline $66-4$ & 590.5 & 1939 & 168 & 71 & 9 & 6 & 3 & 56 & 35 \\
\hline $68-2$ & 606.5 & 978 & 63 & 598 & 7 & 3 & 4 & 42 & 51 \\
\hline $70-3$ & 627.0 & 727 & 70 & 140 & 10 & 6 & 4 & 50 & 40 \\
\hline \multicolumn{10}{|l|}{ Hole 512} \\
\hline $3-2$ & 9.0 & 131 & 29 & - & 22 & 17 & 5 & 30 & 48 \\
\hline $9-2$ & 33.9 & 43 & 14 & - & 32 & 29 & 3 & 39 & 29 \\
\hline $15-2$ & 58.9 & 27 & 6 & - & 21 & 17 & 4 & 54 & 25 \\
\hline \multicolumn{10}{|l|}{ Hole 513} \\
\hline $4-4$ & 34.0 & 93 & 25 & - & 27 & 25 & 2 & 46 & 27 \\
\hline $9-5$ & 83.0 & 42 & 22 & - & 52 & 48 & 4 & 30 & 18 \\
\hline \multicolumn{10}{|c|}{ Hole 513A } \\
\hline $2-6$ & 75.0 & 140 & 47 & 265 & 33 & 31 & 2 & 45 & 22 \\
\hline $5-4$ & 110.0 & 91 & 22 & 129 & 24 & 17 & 7 & 46 & 30 \\
\hline $8-3$ & 137.0 & 96 & 24 & 180 & 25 & 20 & 5 & 52 & 23 \\
\hline $12-3$ & 175.0 & 32 & 15 & 89 & 46 & 38 & 8 & 29 & 25 \\
\hline $15-6$ & 208.0 & 42 & 23 & - & 55 & 23 & 32 & 27 & 18 \\
\hline $17-4$ & 224.0 & 16 & 6 & - & 40 & 33 & 7 & 33 & 27 \\
\hline $20-2$ & 249.3 & 95 & 54 & 172 & 57 & 44 & 13 & 31 & 12 \\
\hline $28-3$ & 327.0 & 50 & 16 & 420 & 32 & 28 & 4 & 36 & 32 \\
\hline $31-6$ & 360.0 & 25 & 9 & 60 & 33 & 30 & 3 & 39 & 28 \\
\hline \multicolumn{10}{|l|}{ Hole 514} \\
\hline $2-2$ & 4.1 & 348 & 224 & 4210 & 64 & 56 & 8 & 31 & 5 \\
\hline $8-2$ & 30.6 & 105 & 37 & - & 35 & 23 & 12 & 43 & 22 \\
\hline $14-2$ & 57.0 & 200 & 14 & 3800 & 8 & 7 & 1 & 54 & 38 \\
\hline $20-2$ & 83.4 & 169 & 19 & - & 11 & 7 & 4 & 52 & 37 \\
\hline $26-2$ & 109.8 & 176 & 20 & - & 11 & 9 & 2 & 57 & 32 \\
\hline $32-2$ & 136.2 & 87 & 11 & - & 13 & 8 & 5 & 60 & 27 \\
\hline
\end{tabular}

a All samples from interval $120-130 / 135 \mathrm{~cm}$.

b Humic acids were not purified by dialysis.

c Not isolated.

$600^{\circ} \mathrm{C}$ for $1 \mathrm{~s}$ using a Chemical Data Systems Pyroprobe 120 -filament pyrolyzer modified for use with a high resolution WCOT fused silica GC column. The pyrolysis effluent was swept, via a $30: 1$ sample splitter, to a $25 \mathrm{~m} \times 0.2 \mathrm{~mm}$ ID fused silica capillary column coated with a SP 2100 liquid phase. Nitrogen was used as a carrier gas, the flow rate through the pyrolyzer adjusted to minimize secondary pyrolysis effects. Following pyrolysis, the GC oven was programmed from $40-$ $270^{\circ} \mathrm{C}$ at $4^{\circ} \mathrm{C} / \mathrm{min}$. Similar conditions were used to record gas chromatograms of the aromatic and saturated hydrocarbon fractions. Aromatic hydrocarbon fractions were analyzed in detail with a CEC110B high-resolution mass spectrometer. Low-ionizing-voltage conditions were employed to measure the intensities of molecular ions from 70-350 mass units with an accuracy of 5-10 millimass units. The general approach to computer processing and interpreting the mass data is like that described by Aczel and Lumpkin (1972).

\section{RESULTS AND DISCUSSION}

In the Initial Core Descriptions of DSDP Leg 71, the black shales at the bottom of the Site 511 core were reported as being highly petroliferous, mature, and al-

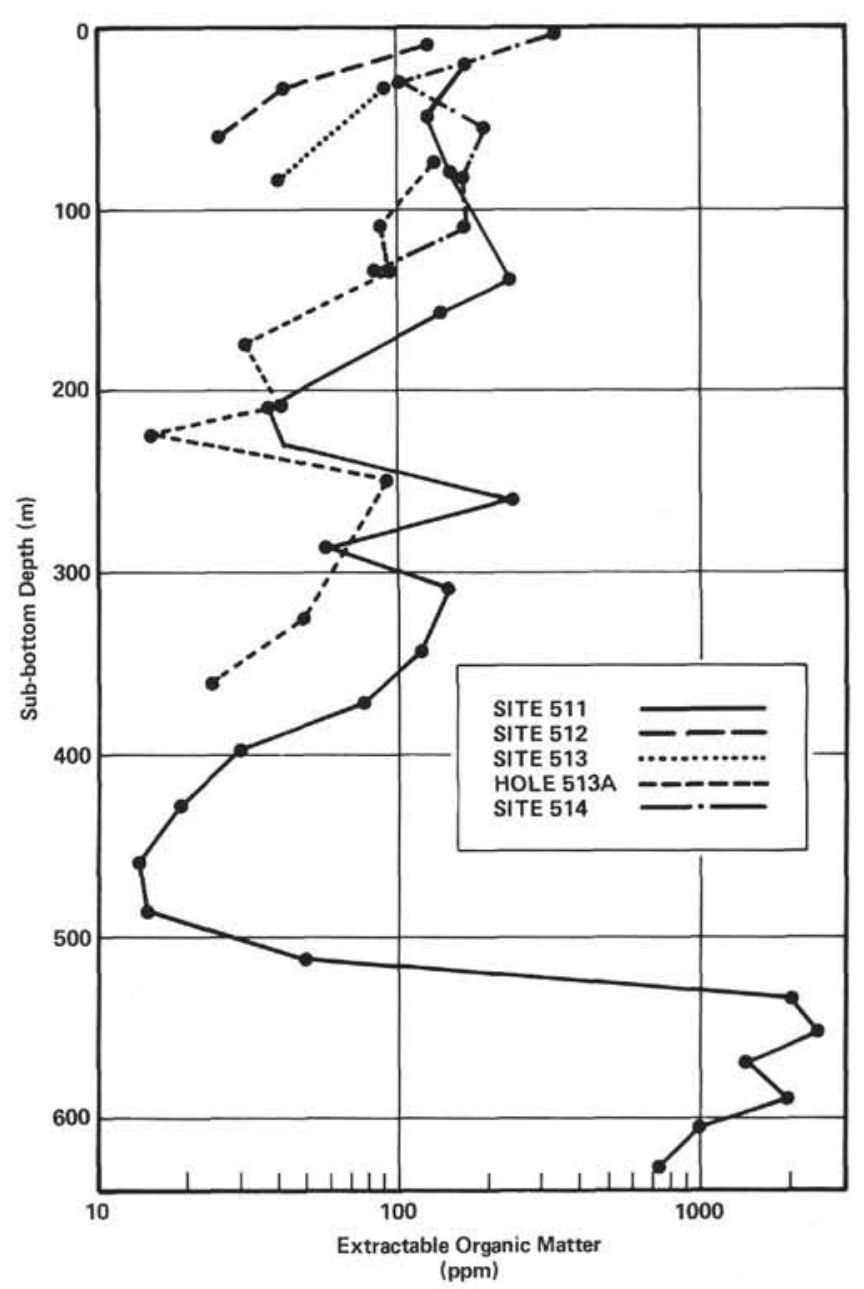

Figure 3. Concentrations of extractable organic matter in samples from DSDP Leg 71.

ready containing some oil or gas. Our work shows (Fig. 3 ) that this interval contains 10 times more EOM than most other Leg 71 sediments. The average EOM concentration is $1590 \mathrm{ppm}$, which is often considered adequate for a crude oil source bed. However, the average hydrocarbon content of the black shale interval is $120 \mathrm{ppm}$, which is marginal compared to the amount of EOM present. Mainly because of these results, our geochemical investigations of Leg 71 core samples were confined predominantly to organic matter from the black shale section of the Site 511 core.

\section{Molecular Analysis of Aromatic Hydrocarbon Fractions}

The only sediment samples which yielded sufficient (>3 mg) aromatics to analyze by high-resolution, lowionizing-voltage mass spectrometry were Cores 60 through 70 from Hole 511. The molecular type-carbon number distributions of the aromatic hydrocarbons and the $\mathrm{S}$-and $\mathrm{O}$-heterocyclic compounds in the aromatics fraction from Section 511-66-4 are shown in Figure 4. The aromatic fractions from the other core samples from the same interval had similar molecular type distributions. Aromatic molecular types from benzenes (Z-6) 


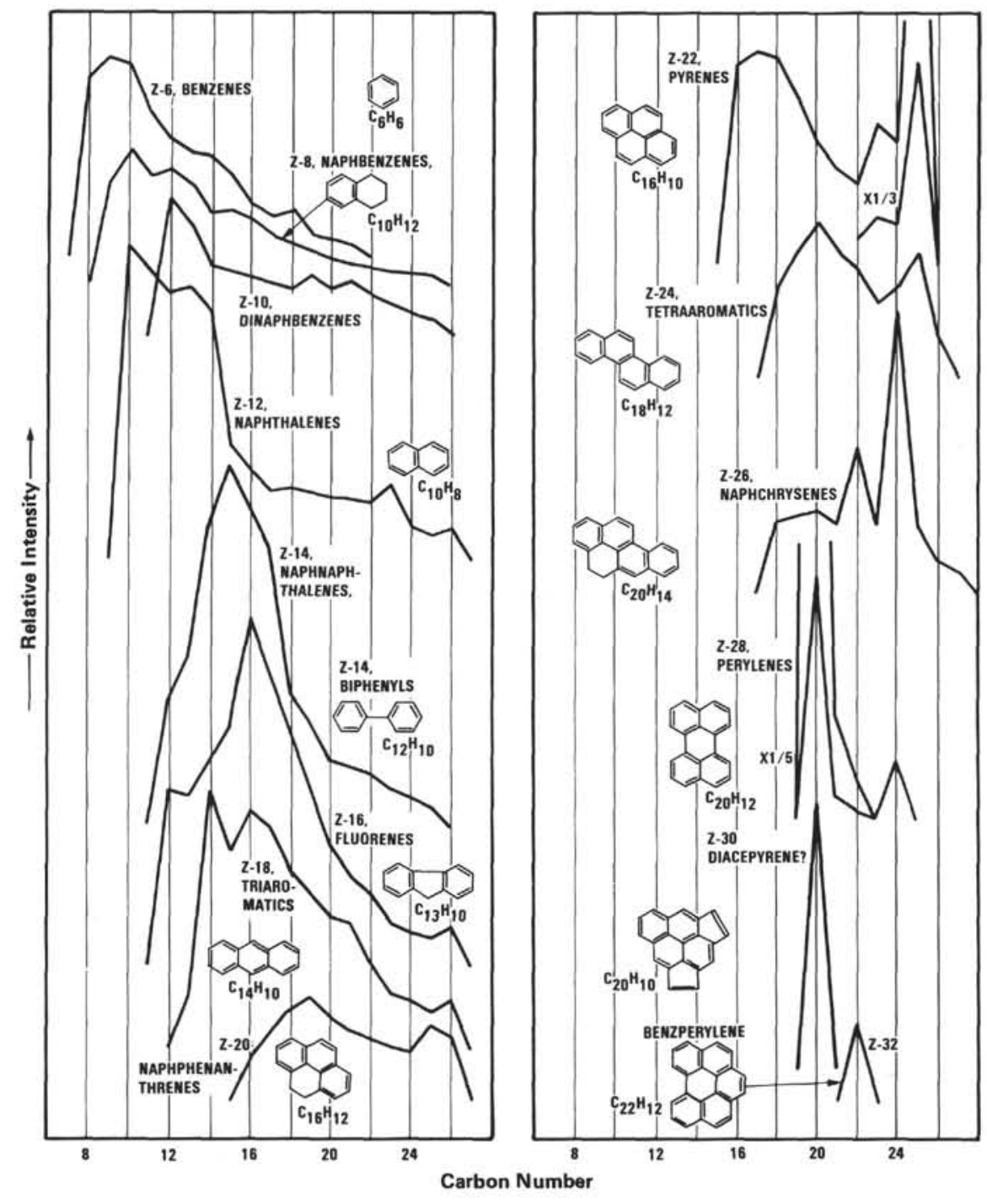

Figure 4. Molecular type-carbon number distributions of aromatic hydrocarbons and S- and O-heterocyclic compounds from Section 511-66-4. Ends of distribution curves are at zero intensity.

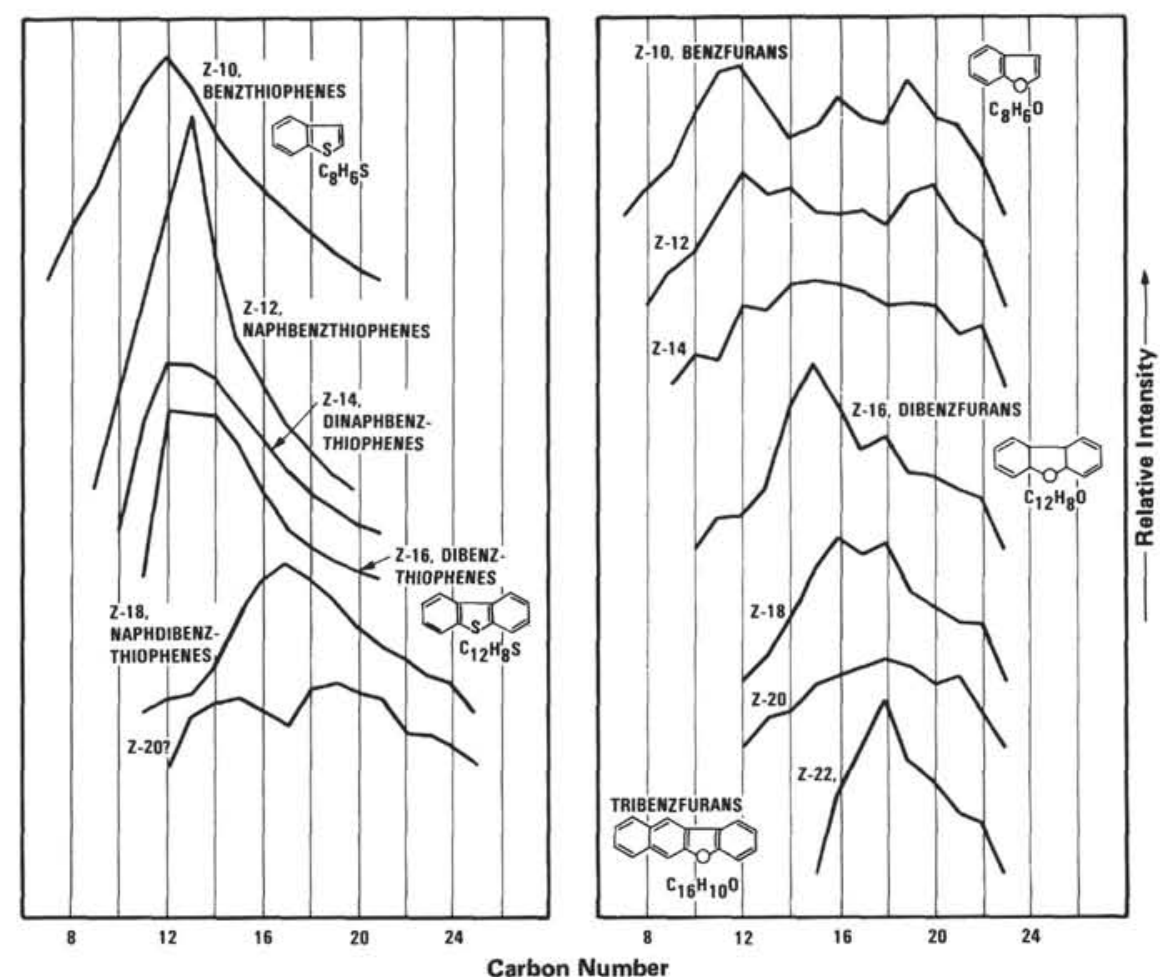

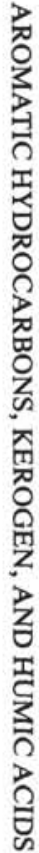


through naphchrysenes (Z-26) (Fig. 4) have distributions which are like those found in crude oils (Rullkötter and Welte, 1981). In addition, there are sharp maxima from $\mathrm{C}_{22}$ to $\mathrm{C}_{25}$ in the distributions for pyrenes (Z-22), tetraaromatics (Z-24), and naphchrysenes (Z-26). These maxima are not caused by sterenes, because the accurately determined mass weights are those of polynuclear aromatics, not sterenes, and the sterenes were eluted with the saturated hydrocarbons in the elution chromatographic separation steps. The most abundant single molecular type in Figure 4 is perylene $\left(\mathrm{Z}-28, \mathrm{C}_{20} \mathrm{H}_{12}\right)$, a common constituent of sediments (Aizenshtat, 1973). Alkyl derivatives of perylene are minor. Benzperylene $\left(\mathrm{Z}-32, \mathrm{C}_{22} \mathrm{H}_{12}\right)$ is present without homologs. The single molecular type for the Z-30 distribution has been tentatively assigned the structure of diacepyrene $\left(\mathrm{C}_{20} \mathrm{H}_{10}\right)$.

Aromatic thiophenes and furans were identified in the aromatic fractions, and their molecular distributions are shown on the right side of Figure 4. The distributions of the components are similar to those of many crude oils, and the relative abundances of the various subtypes are very similar. Tribenzfurans (Z-22) are present, but tribenzthiophenes (Z-22) were not detected.

Gas chromatograms of the aromatic hydrocarbon fractions from the black shale interval of Site 511 were very similar. Also, the complementary saturate fractions produced gas chromatograms which were generally alike. An example (from Section 511-66-4) of a chromatogram of each type is shown in Figure 5. The aromatic hydrocarbon fractions were very complex mixtures, and those few peaks that could readily be identified by Retention Index are so marked in Figure 5. The general appearance of the saturates gas chromatogram shown in Figure 5 indicates the black shales may potentially become crude oil source rocks. The pristane/phytane ratio is about 0.5 , and a complex assemblage of steroidal hydrocarbons is present between $C_{25}$ and $C_{32}$. The relatively high abundance of $n$-alkanes in the $\mathrm{C}_{17}-\mathrm{C}_{24}$ region indicates a predominantly marine source. The high CPI

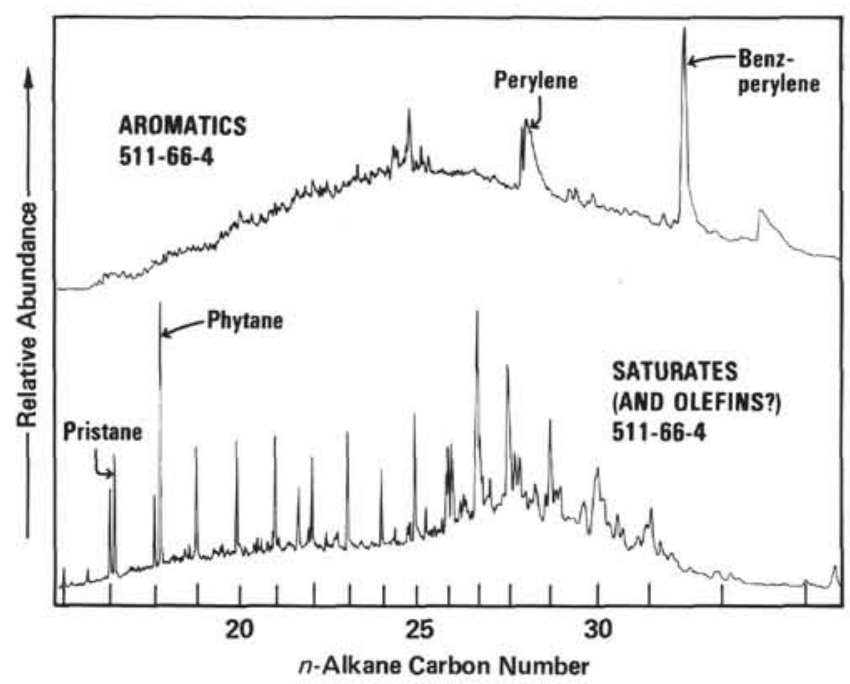

Figure 5. Gas chromatograms of aromatic and saturated hydrocarbon fractions from Hole 511 black shale samples. of the $n$-alkanes in the $\mathrm{C}_{25}-\mathrm{C}_{31}$ region suggests a relatively low rank level for the organic matter in this section. This may explain why the gas chromatographic fingerprint of the aromatic hydrocarbon fraction in Figure 5 is not like that from a thermally mature sediment or petroleum. These observations of low rank level of organic matter, together with similar results in the kerogen and humic acid work to be described, suggest that the hydrocarbons in the black shale section of Hole 511 are not entirely of a thermal origin. They appear to be predominantly hydrocarbons preserved in the sediments since their initial deposition.

\section{Pyrolysis Gas Chromatography of Humic Acid and Kerogen Fractions}

Figure 6 shows pyrolysis gas chromatograms (pyrograms) of the humic acid and kerogen fractions from Sections 511-68-2 and 511-64-4, respectively. The pyrograms are typical for the humic acids and kerogens from the interval, rich in organic matter, at the bottom of Hole 511 core, both materials having pyrolysates characterized by abundant products, particularly $n$-alkenes and $n$-alkanes, with less than 20 carbon atoms. Although the pyrograms do contain higher molecular weight material, it represents only a minor fraction of the whole pyrolysate. A dominance of relatively low molecular weight aliphatic materials in the pyrograms is typical of geopolymers derived from marine algal material (van de Meent et al., 1980).

The peak eluting near 1730 (Retention Index) position in both pyrograms in Figure 6 is tentatively identified as prist-1-ene (Larter et al., 1979). $\mathrm{A} \mathrm{C}_{14}$ isoprenoid alkene is similarly identified eluting between the $n-C_{13}$ alkene and alkane. A like abundance of both $\mathrm{C}_{14}$ and $\mathrm{C}_{19}$ isoprenoid moieties was noted in pyrograms of marine, algally derived kerogen from the Cariaco Trench (van de Meent et al., 1980), and indeed the pyrogram fingerprints from both studies are very similar.

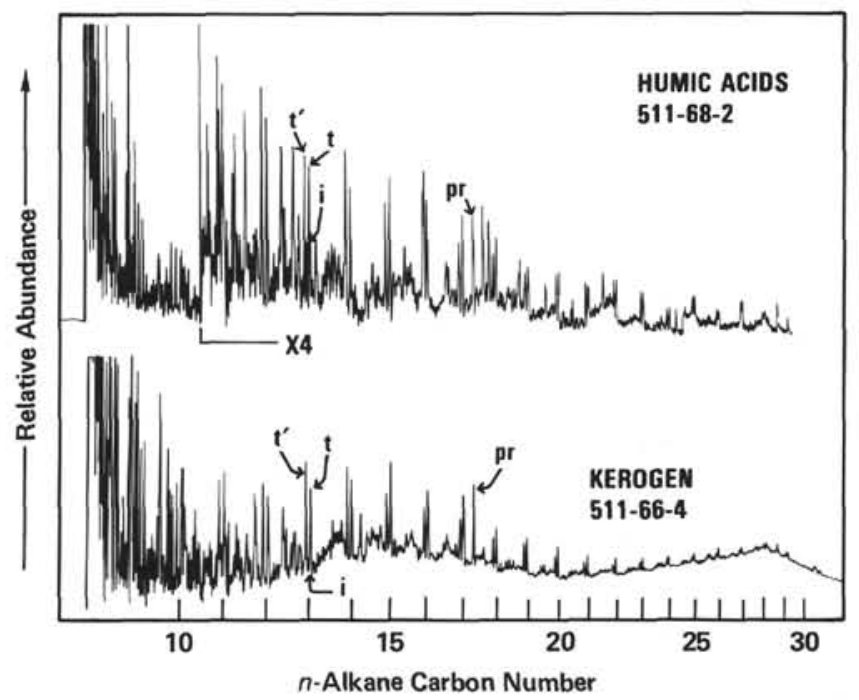

Figure 6. Pyrograms of kerogen and humic acids from Hole 511 black shale core samples. $\mathrm{i}=\mathrm{C}_{14}$ isoprenoid alkene; $\mathrm{pr}=$ prist-1-ene; $\mathrm{t}=n-\mathrm{C}_{13}$ alkane; $\mathrm{t}^{\prime}=n-\mathrm{C}_{13}$ alkene. 
Visual kerogen analysis indicated that the kerogens from Site 511 black shales are composed almost entirely of relatively low rank, amorphous material similar in appearance to many marine kerogens. This kerogen type was found throughout Hole 511 with varying amounts of admixed terrigenous material down to the black shale section. Elemental analysis indicated that the kerogen in the black shales has atomic $\mathrm{H} / \mathrm{C}$ ratios as high as 1.3. Although there are differences between the humic acid and kerogen pyrograms in Figure 6, the similar molecular weight range of the pyrolysate components, the abundant presence of specific pyrolysate components in both pyrograms, and a general similarity of the pyrogram fingerprints suggest that both humic acid and kerogen were derived from a common marine, lipid stock. It has been suggested that humic acids represent a kerogen progenitor phase (Huc and Durand, 1977). The data presented here certainly suggest a common, if not sequential, origin for both materials.

\section{Comparison with Geochemical Results for Site 330 and Hole 327A, DSDP Leg 36}

Site 511 , DSDP Leg 71 , is located about $10-15 \mathrm{~km}$ south of Sites 327 and 330, DSDP Leg 36, in the basin province of the Falkland Plateau. Comer and Littlejohn (1977) analyzed samples from Site 330 and Hole 327A for organic matter content and maturity. Sapropelic claystones equivalent in age to the black shale interval of Site 511 occur in the middle of Hole 330 and the lower third of Hole 327A. (The ages of the black shale interval of Site 511 were just revised to Albian-Aptian through Barremian for Cores 58 to 60 and Tithonian through Kimmeridgian for Cores 63 to 70.) In those intervals Leg 36 sapropelic claystones contain predominantly amorphous kerogen and an average of $287 \mathrm{ppm}$ of EOM. In comparison, the organic matter in the Site 511 black shale interval is also amorphous but contains more than five times as much EOM.

\section{CONCLUSIONS}

The black shales at the bottom of Hole 511 contain ten times more extractable organic matter than most other Leg 71 sediments. Based on EOM (1590 ppm) and hydrocarbon $(120 \mathrm{ppm})$ contents alone, this interval would classically be considered a potential source bed for crude oil. The composition of the organic matter ( $n$-alkane CPI, percentage of hydrocarbons, kerogen $\mathrm{H} / \mathrm{C}$ ratio, etc.), however, suggests that the interval has not reached full thermal maturity. These data and the low rank of this section indicate that many of the hydrocarbons were deposited with the original sediments.
One- through four-ring aromatic hydrocarbons from the black shale interval have molecular type-carbon number distributions which are similar to those of many petroleums. The overall aromatic hydrocarbon gas chromatographic fingerprint, however, is not like that from a thermally mature sediment or petroleum. Mono- and dibenzthiophenes and mono-, di-, and tribenzfurans are also present. Both heterocyclic types have carbon number distributions similar to those of many crude oils.

Pyrograms of the humic acids and kerogens from the black shale interval of Hole 511 are very similar. The general fingerprint of the pyrograms is typical of geopolymers derived from marine algal material. Indeed, humic acids and kerogens here may be derived from the same lipid stock. Visual analysis of the kerogen indicates it is composed entirely of low rank, amorphous material similar in appearance to many marine kerogens. Above the black shale interval the amorphous kerogen is admixed with varying amounts of terrigenous material.

\section{ACKNOWLEDGMENTS}

The authors wish to thank the Union Oil Company of California for permission to carry out and publish this work. Sample separations were capably carried out by C. J. Moderow. Manuscript review and suggestions for improvement were made by Drs. G. H. Smith and R. E. Sweeney.

\section{REFERENCES}

Aczel, T., and Lumpkin, H. E., 1972. Detailed characterization of gas oils by high and low resolution mass spectrometry. 164th Natl. ACS Mtg. (New York, 8/27/72), Div. Petrol. Chem. Preprints, F66-F80.

Aizenshtat, Z., 1973. Perylene and its geochemical significance. Geochim. Cosmochim. Acta, 37: 559-567.

Comer, J. B., and Littlejohn, R., 1977. Content, composition and thermal history of organic matter in Mesozoic sediments, Falkland Plateau. In Barker, P. F., Dalziel, I. W. D., et al., Init. Repts. DSDP, 36: Washington (U.S. Govt. Printing Office), 941-944.

Huc, A. Y., and Durand, B. M., 1977. Occurrence and significance of humic acids in ancient sediments. Fuel, 56: 73-80.

Ishiwatari, R., Ishiwatari, M., Rohrback, B. G., and Kaplan, I. R., 1977. Thermal alteration experiments on organic matter from Recent marine sediments in relation to petroleum genesis. Geochim. Cosmochim. Acta, 41: 815-828.

Larter, S. R., Solli, H., Douglas, A. G., de Lange, F., and de Leeuw, J. W., 1979. Occurrence and significance of prist-1-ene in kerogen pyrolysates. Nature, 279: 405-408.

Rullkötter, J., and Welte, D. H., 1981. in press. Oil-oil and oil-condensate correlation by low eV GC-MS measurements of aromatic hydrocarbons. Adv. Org. Geochem., 1979: New York (Pergamon Press), pp. 93-102.

van de Meent, D., Brown, S. C., and Philp, R. P., 1980. Pyrolysishigh resolution gas chromatography and pyrolysis gas chromatography-mass spectrometry of kerogens and kerogen precursors. Geochim. Cosmochim. Acta, 44: 999-1013. 